\title{
Pulses of ocean acidification at the Triassic-Jurassic boundary recorded by boron isotopes
}

\author{
MOLLY TRUDGILL ${ }^{1}$, JAMES W. B. RAE ${ }^{1}$, JESSICA \\ CRUMPTON-BANKS ${ }^{1,2}$, MICHAEL VAN MOURIK ${ }^{1}$, \\ MARKUS ADLOFF ${ }^{3,4}$, ANDREA BURKE ${ }^{1}$, FRANK \\ CORSETTI $^{5}$, DANIEL DOHERTY ${ }^{4}$, ROSANNA GREENOP ${ }^{1}$, \\ WEI-LI HONG ${ }^{6}$, AIVO LEPLAND ${ }^{7}$, ANDREW MCINTYRE ${ }^{1}$, \\ NOOR NEIROUKH ${ }^{1}$, CATHERINE ROSE $^{1}$, MICHA RUHL ${ }^{8}$, \\ DAVID SAUNDERS ${ }^{1}$, EVA E. STÜEKEN ${ }^{1}$, JOSHUA WEST ${ }^{5}$, \\ ROSS WHITEFORD ${ }^{1}$ AND SARAH GREENE ${ }^{4}$ \\ ${ }^{1}$ University of St Andrews \\ ${ }^{2}$ National University of Ireland Galway \\ ${ }^{3}$ University of Bristol \\ ${ }^{4}$ University of Birmingham \\ ${ }^{5}$ University of Southern California \\ ${ }^{6}$ Department of Geological Sciences, Stockholm University \\ ${ }^{7}$ Geological Survey of Norway \\ ${ }^{8}$ Trinity College Dublin \\ Presenting Author: mdt2@st-andrews.ac.uk
}

\begin{abstract}
Mass extinctions have repeatedly perturbed the history of life, with ocean acidification often invoked as a potential kill mechanism; however, direct evidence for a link between $\mathrm{pH}$ and biodiversity in the geologic past remains limited. In particular, at the end-Triassic mass extinction event preferential extinction of heavily calcified groups, paired with changes in shallow carbonate deposition, hint at acidification as a causal mechanism, but these observations can also result from other factors. Furthermore, depending on the rates of volcanic input and the efficiency of buffering by the carbonate system, volcanic emissions may not necessarily result in appreciable carbonate undersaturation. Here we examine the link between $\mathrm{pH}$ and mass extinction events in the rock record, presenting the first $\mathrm{pH}$ reconstruction over the Triassic-Jurassic boundary together with evidence from other novel tracers and time periods. These data, generated using the boron isotope composition of well-preserved fossil oyster shells, reveal a pronounced acidification pulse in the aftermath of the end-Triassic extinction, coincident with input of isotopically light carbon and ocean warming. This signal is consistent with ocean acidification caused by pulses of volcanic carbon input from the Central Atlantic Magmatic Province, supporting the hypothesis that ocean acidification was an important component of large igneous province-associated mass extinctions.
\end{abstract}

